\title{
Avaliação ou Exame: O que praticamos no cotidiano do ensino de Matemática?
}

Marco Aurélio Kistemann Jr. Ruth Brugger Glanszmann

\section{Resumo}

O presente artigo busca apresentar reflexões e teorizações acerca do tema Avaliação. Tais reflexões buscam convidar os educadores a questionarem suas práticas pedagógicas e ao mesmo tempo recordarem o que significa avaliar e examinar, bem como as consequências dessas ações desprovidas de qualquer neutralidade no cotidiano escolar. Nesse sentido, nos embasamos em teóricos como Cipriano Luckesi, Philippe Perrenoud e Jussara Hoffman. Destacamos que o tema da Avaliação ainda constitui-se como um tabu em boa parte dos contextos escolares da educação básica ou universitária. A qualidade da aprendizagem discente, entendemos, está diretamente relacionada com as propostas metodológicas docentes.

Palavras-chave: Avaliação, Exame, Inclusão, Aprendizagem. 


\title{
Assessment or Exam: What do we practice in the everyday teaching of mathematics?
}

\author{
Marco Aurélio Kistemann Jr. \\ Ruth Brugger Glanszmann
}

\section{Abstract}

The present article seeks to present reflections and theorizations about the theme Evaluation. These reflections seek to invite educators to question their pedagogical practices and at the same time to remember what it means to evaluate and examine, as well as the consequences of these actions devoid of any neutrality in the daily school life. In this sense, we rely on theoreticians like Cipriano Luckesi, Philippe Perrenoud and Jussara Hoffman. We emphasize that the theme of Evaluation still constitutes a taboo in most of the school contexts of basic or university education. The quality of student learning, we understand, is directly related to the methodological proposals of teachers.

Keywords: Assessment, Exam, Inclusion, Learning. 


\section{Palavras Iniciais}

Este artigo, de cunho teórico, objetiva apresentar as angústias de dois pesquisadores na área de Avaliação interna e externa. Objetiva ainda apresentar questionamentos que permearam o percurso desses pesquisadores, ainda como estudantes da educação básica e depois na educação superior. Sempre nos questionamos os porquês de um sistema escolar tão rígido com aulas de 50 minutos, provas e testes individuais e aprovações/reprovações, muito ensino e frágeis aprendizagens. Nesse contexto, buscamos possibilitar ao leitor um diálogo que promova reflexões e questionamentos sobre nossas práticas pedagógicas em nossos ambientes escolares e universitários.

Afinal a escola não é o lugar para o qual mandamos gerações de estudantes para aprender? Então por que a reprovação? A exclusão de muitos que querem aprender e tem seu tempo diferenciado e desrespeitado em nome de protocolos, relatórios e índices vai se prolongar até quando? Avaliamos pouco, examinamos todos, essa fórmula é irreversível, após tantas pesquisas sobre a aprendizagem matemática significativa e os resultados cada vez mais desafiadores de paradigmas das Neurociências?

Deve ficar claro para o leitor que nossas concepções epistemológicas acerca da Educação, da Educação Matemática e do ensino de Matemática e Formação de Professores nos guiam rumo à inclusão de cada estudante. É fato que o conteúdo matemático a ser ensinado e aprendido é importante, mas, mais importante é que o estudante mediado pelo professor e que este o avalie em suas diversas competências. Isso transcende a prática de corrigir teste e provas e dar um índice (nota ou conceito) e crer que esse índice representa o estudante.

A palavra Avaliação, ao longo do século XX e nas duas primeiras décadas do século XXI, conjecturamos seja a palavra mais enunciada nos ambientes escolares e espaços educacionais governamentais, tanto no Brasil, quanto nos demais países. Por quê?

A resposta a essa pergunta pode querer justificar toda a preocupação que deve existir com a aprendizagem dos alunos, entretanto, os resultados em avaliações externas e internas vêm mostrando que a aprendizagem muitas vezes fica coadjuvante, num segundo plano, sem que nos percebamos que, em geral, ambiciona-se avaliar as aprendizagens discentes, mas acaba-se por examinar conteúdos programáticos, o que incorre, inicialmente em verificar se certos conteúdos foram ou não bem assimilados pelos estudantes por meio de instrumentos ditos avaliativos.

É possível verificar que muitos professores falam, escrevem e têm até vontade de avaliar, porém falham em seus atos, não se sentem à vontade e seguros para avaliar, ficam frustrados, pois nunca foram, de fato, formados para serem avaliadores, mas vivenciaram em suas formações práticas de exames, provas individuais, médias, notas aprovações e reprovações. Questionamos, como ser um professor-avaliador se só foram vivenciados quadros 
de formação de professor-examinador em sua trajetória de formação?

Reflitamos sobre como são feitas as "avaliações" no século XXI e suas analogias com as "avaliações” realizadas há alguns séculos. Em geral, os professores decidem a data das mesmas, o conteúdo que será avaliado, o tempo que será gasto, quanto valerão as questões, os critérios de correção e se o estudante será promovido ou não no fim do ano. Está muito diferente dos séculos passados?

O progresso em diversas áreas (sociais e tecnológicas) vêm ocorrendo de forma acentuada ao longo dos tempos. Entretanto, na área educacional as mudanças ainda são lentas, esbarram em burocracias, sofrem resistências, muitas vezes por questões político-ideológicas. Nesse contexto, faz-se necessário reflexões que busquem colocar em evidência, o que significa avaliar, buscar o processo em detrimento do ato pontual e isolado de avaliar, regular a aprendizagem, privilegiar o conhecimento prévio do aluno, utilizar a nota como mais um dos referenciais diagnósticos.

O presente artigo busca discutir algumas questões colocadas anteriormente, reservando-se ao contexto da Avaliação em Matemática, embora mereça ser colocado que muito do que será aqui discutido possa ver verificado, resguardadas as devidas proporções, nas demais áreas do conhecimento escolar. Utilizaremos em variados momentos das reflexões do pesquisador brasileiro Cipriano Carlos Luckesi e do pesquisador suíço Philippe Perrenoud e de experiências vivenciadas pelo autor do presente artigo em seus cursos de formação de professores na Licenciatura em Matemática na UFJF.

Desse modo, pretendemos na primeira parte apresentar uma análise crítica sobre a prática da Avaliação da Aprendizagem em Matemática em nossas escolas, nas quais, podemos observar praticam-se Exames e diz-se praticar Avaliação. Com raras exceções, vivencia-se nos ambientes escolares, de todos os níveis, a Cultura do Exame, práticas que mais têm servido à classificação do que ao diagnóstico e à tomada de decisão em favor de melhores resultados (LUCKESI, 2009).

Precisamos esclarecer que em nossa experiência em ministrar disciplinas na graduação diurna e noturna em Matemática, diversos são os depoimentos discentes com relação a não problematização de temas como Avaliação. Ressaltamos que essa discussão é escassa nos cursos de licenciatura e o número de reprovações em certas disciplinas em Ciências Exatas é histórica, com alta retenção, evasão e ensino houve, e a aprendizagem?

Na segunda parte, discutiremos porque pratica-se Exame ao invés de Avaliação em Matemática traçando algumas referências históricas para sustentar uma escolha avaliativa.

Na terceira parte, enfocaremos formas de viabilizar possibilidades da Avaliação da Aprendizagem em Matemática e de que forma pode-se praticar o ato avaliativo em Matemática buscando consagrar formas diagnósticas e inclusivas. 
Ao finalizar o artigo, buscamos localizar os usos da Avaliação em Matemática e do Exame em Matemática na escola dos dias atuais, apresentando possibilidades de se pensar e executar a Avaliação de uma forma diagnóstica e inclusiva.

\section{Avaliação da Aprendizagem em Matemática - Praticar Avaliação ou Exame?}

Conforme já foi explicitado, a palavra Avaliação é muito utilizada nos discursos pelos diversos agentes escolares. É comum ouvir os professores se dirigindo aos alunos: "Amanhã é a avaliação de Matemática, estudem!".

Será mesmo que amanhã, segundo o pronunciamento do professor, ocorrerá Avaliação de Matemática? Segundo Luckesi (2009, p.15),

(...) hoje na escola brasileira, pública ou particular, dos níveis de ensino fundamental, médio ou superior, praticamos exames escolares, ao invés de avaliação da aprendizagem. A partir dos anos setenta, do século passado, passamos a denominar a prática escolar de acompanhamento da aprendizagem do educando de "avaliação da aprendizagem escolar", mas, na verdade, continuamos a praticar "exames escolares".

Para orientarmos nossa discussão faz necessário explicitar o que entendemos por Avaliação e o que entendemos por Exame. É mister citar que, o ato de avaliar desvincula-se totalmente do ato de Examinar. O professor de Matemática que avalia é distinto do professor de Matemática que examina. Da mesma forma que podemos crer que os órgãos governamentais, que acreditam avaliar, têm somente e, de forma ingênua, examinado a aprendizagem matemática. Em suma, em nossa concepção pedagógica e epistemológica, avaliamos saberes enunciados por estudantes, suas produções de significados e examinamos dados apresentados em instrumentos como testes, provas e similares.

Os Exames escolares de Matemática, em geral através de seu instrumento-mor, as provas $^{19}$, tem se caracterizado de acordo com Perrenoud (2004) por:

- julgar e, consequentemente, aprovar ou reprovar os alunos em sua trajetória nas séries escolares. Esse poder de aprovar/reprovar é o argumento sustentador significativo para a manutenção da Cultura do Exame;

- restringir-se ao que vai cair nas provas, na medida em que o aluno deve saber responder às questões matemáticas aqui e agora, em cinqüenta minutos, não importando se o aluno sabia antes e confundiu-se no momento do teste, nem se importando se o mesmo virá a saber depois do evento examinativo. O que importa é o momento, o agora;

- classificar estabelecendo uma escala de valores, com um ponto referencial, a partir do

${ }^{19}$ As provas, testes e simulados são os recursos através dos quais os exames são realizados. Os exames compõem a modalidade de aferição da aprendizagem, as provas coletam os dados que dão base aos exames e que serão convertidos em notas, afim de que, mais tarde, haja a certificação dos alunos. 
qual, para mais aprova, para menos, reprova, selecionando na medida que excluem os que "não sabem os conteúdos matemáticos abordados”, no contexto dos parâmetros considerados aceitáveis pelos examinadores;

- $\quad$ romover práticas pedagógicas autoritárias que se baseiam em classificar os alunos através de números, estabelecendo médias que comporão uma escala. Matematicamente preciso, porém revelador de um processo antidemocrático e, consequentemente excludente, colocando nas mãos dos professores um instrumento de poder, cuja autoridade pode ser exacerbada em autoritarismo. Com os exames em mãos, os educadores, representando o sistema social, no geral, têm servido desse recurso para controlar disciplinarmente os educandos;

Por outro lado, inspiramo-nos em Hoffman (2011) para defender que as Avaliações escolares de Matemática, contrapõem-se totalmente aos Exames escolares de Matemática, pois caracterizam-se por:

- diagnosticar a situação de aprendizagem do aluno, objetivando subsidiar a tomada de decisões para a melhoria da qualidade do desempenho desse aluno ao longo do processo de construção do conhecimento matemático;

- privilegiar o caráter processual e diagnóstico, admitindo que em um dado momento, de fato, pode o aluno não saber integralmente como operar com determinado tema matemático, mas se mediado pelo professor e pela interação com seus colegas, poderá alcançar os objetivos almejados. É pensar no caráter provisório em que se encontra o aluno, em oposição ao caráter definitivo que promove a exclusão, ou seja, não sabe logo deve ser penalizado por não saber;

- incluir, ou seja, não estabelece de forma engessada que o aluno não sabe e que o momento de saber é aquele, isto, é classifica o educando em um determinado nível de aprendizagem estático, atemporal, a-histórico e descontextualizado. Na medida em que não seleciona ou ranqueia os alunos em melhores ou piores, em capazes ou incapazes, em os que têm ou não dom para a Matemática, o professor toma decisões e subsidia a busca de meios pelos quais todos podem aprender visando o desenvolvimento, cada qual no seu ritmo, do aluno;

- privilegiar práticas pedagógicas dialógicas entre professores e alunos buscando de forma efetiva o objetivo de aprender e aprender a aprender, de modo que, a avaliação exige uma interação permanente entre professor e aluno, interação onde o professor deve atuar de forma mediadora, tanto na ação de ensinar quanto na ação de avaliar;

- investigar através de variados instrumentos avaliativos de que forma se dá a ISSN 2526-2882 
construção do conhecimento matemático por parte dos alunos; que obstáculos cognitivos se colocam nos diálogos que o aluno trava com a Matemática; que estratégias privilegiam a aprendizagem de Matemática através da análise das avaliações.

Analisando as duas caracterizações apresentadas anteriormente, podemos considerar que, em grande parte do contingente educacional brasileiro, o que ainda se pratica nas escolas é o Exame. Para Luckesi (2009), usualmente não diagnosticamos nossos alunos para subsidiar uma intervenção adequada e inclusiva. O que ocorre é o contrário, classificamo-os, tendo em vista aprová-los ou reprová-los, criar rankings ou hierarquias de excelência (PERRENOUD, 1999), fatos este que conduzem a práticas com as características: anti-democrática, classificatória, seletiva, pontual e estática. Desse modo, inferimos que, em particular, nas salas de aula de Matemática, praticam-se Exames e denominam-se, inadequadamente, essa prática de Avaliação da Aprendizagem Matemática.

Na lógica dos Exames, que em nada assemelham-se à lógica da Avaliação, opera-se com os resultados de aprovação/reprovação, isto é, sabe os conteúdos matemáticos como foram ensinados então passa, não sabe, fica retido e repete tudo de novo. Esta aí revelado o fracasso escolar e sua origem reside na incapacidade do estudante em assimilar conceitos matemáticos, em tempos demarcados pelo professor e reproduzi-los em situações particulares e também bem delimitadas.

Superar esse fracasso na disciplina de Matemática significa, prioritariamente, investir na qualidade do ensino, que deve ter como desaparecimento direto a reprovação, como hoje é praticada. Segundo Perrenoud (2004, p. 56), ”...quem efetivamente aprende, a partir de um ensino de boa qualidade, não pode ser penalizado com a reprovação. Um ensino de boa qualidade investe na aprendizagem e não retenção". Diversos são os depoimentos de professores sobre a situação de alunos reprovados que, se tivessem tido regulações diferenciadas, formatos diferentes de verificação de aprendizagem, além de testes e provas, poderiam ter aprendido de forma significativa e teriam sido aprovados no término do ano letivo.

Luckesi (2009) salienta que a prática dos exames, devido a operar com os recursos de aprovação/reprovação, conduz, irreversivelmente, à política da retenção e da exclusão que tem se manifestado como o mais consistente álibi para o fracasso escolar. Para o pesquisador, o discurso mais comum é: "Já que os alunos não aprenderam, devem ficar retidos na série, pois não comprovaram saber os conteúdos oferecidos pelo professor; não é possível continuar promovendo educandos que não tenham aprendido Matemática, por exemplo”.

Assim, de acordo com Luckesi (2009) tranquilizamos nossa consciência e não aprofundamos a investigação das verdadeiras causas do fracasso escolar, que têm muito mais 
a ver com má qualidade de ensino do que com incompetência ou má vontade dos alunos. A realidade é complexa e em Matemática mais ainda, pois a rejeição à disciplina vem crescendo em todo país, atingindo já as séries iniciais.

Os exames realizados nos diversos estados, aos moldes dos exames internacionais têm revelado a calamitosa situação do ensino da disciplina. Ter medo da Matemática, ter medo de não aprender os conceitos, por muito considerados inatingíveis, de outro planeta, ter medo de ficar retido e repetir tudo de novo. A Cultura do Exame alicerça-se no medo, na insegurança, na humilhação, na exclusão e na frustração.

Ao professor cabe refletir, e aprender com os conhecimentos históricos sobre exames e avaliação, questionar-se, e por fim, escolher que práticas deseja colocar em ação. É preciso que fique claro que as escolhas feitas, revelam o grau de comprometimento do profissional com a melhoria da qualidade do ensino de Matemática. Não podemos conceber que práticas pedagógicas sejam realizadas e mal denominadas, buscando objetivos que não serão atingidos enquanto avaliarmos com propostas examinativas.

\section{Praticando o Exame - Protelando a Avaliação em Matemática - Referências Históricas}

Na década de 1930 do século passado, Tyler²0 sugeriu a denominação "Avaliação da Aprendizagem", conceituando, assim, a prática que oferecia o diagnóstico do curso das aprendizagens dos educandos na escola, buscando subsídios para torná-la mais eficaz e produtiva. Ao longo dos anos essa denominação, de acordo com Luckesi (2009), passa generalizada e equivocadamente, a indicar toda e qualquer atividade de aferição do aproveitamento escolar.

O resultado desse equívoco é que diferenciados fenômenos passaram a ser denominados de avaliação. Exames, seleções de pessoas, passam a ser consideradas avaliações e a Avaliação, propriamente dita, também se insere nessa denominação. Uma sucessão de denominações distintas com aspecto de avaliação, mas espírito de exame, seleção, exclusão e fracasso escolar.

Em Matemática, mais do que em qualquer outra disciplina, esses termos, exame e avaliação, expressam conceitos diametralmente opostos. Muitos professores dizem que Avaliar é muito complicado, sugerem como obstáculo as turmas lotadas, falta de equipamentos, desinteresse dos alunos e ainda a necessidade de julgar (aprovar/reprovar). Essa, no entanto, é a dificuldade do ato de Examinar, nunca do ato de Avaliar. Conforme já explicitamos, em

\footnotetext{
${ }^{20}$ Ralph Tyler, educador norte-americano que nos idos dos anos 1930, do século XX, formulou o ensino por objetivos e criou uma forma de proceder a avaliação da aprendizagem, de tal forma, que garantisse a qualidade de um ensino-aprendizagem eficiente. Foi nesse contexto que cunhou o termo Avaliação da Aprendizagem.
} ISSN 2526-2882 
Avaliação não se julga, não se classifica ou se ranqueia aluno, mas sim se diagnostica, intervindo em favor da melhoria da aprendizagem e dos resultados do desempenho dos alunos, respeitando o ritmo e o tempo de aprendizagem escolar de cada estudante.

Por que praticar atos examinativos ao invés de optar-se por atos avaliativos? O que impede os professores de Matemática de proceder práticas avaliativas, em detrimento de práticas examinativas que sabem de antemão excluirão a maioria dos alunos do acesso à aprendizagem dos conceitos matemáticos?

Descreveremos a seguir três razões que compartilho com alguns autores, em particular com Luckesi (2009) e Hoffman (2011).

A primeira razão que nos remete à prática dos exames ancora-se em sua longa tradição histórica de mais de quatro séculos. De acordo com LUCKESI (2009), os exames escolares que hoje permeiam o cotidiano escolar, foram sistematizadas nos séculos XVI e XVII, com as configurações pedagógicas produzidas pelos padres jesuítas (séc.XVI) e pelo bispo protestante John Amós Comênio (fins do séc.XVI e primeira metade do XVII). Tal fato influencia até os dias atuais nossas condutas pedagógicas e avaliativas.

É preciso recordar que exames já existiam muito antes desse período no oriente. $\mathrm{Na}$ China, em torno de três mil anos antes da era cristã, a fim de proceder à seleção de homens para o exército, porém, “exames escolares”, como são praticados, atualmente, nas salas de aula foram sistematizados com o advento da modernidade e sua consequente prática avaliativa.

Para efeitos de comparação, a instituição "escola” medieval é distinta da nossa escola atual, uma vez que naquela época a escola era composta do mestre e um ou dois aprendizes. A escola dos dias atuais é a escola em que um ensina (o regente da turma) e muitos (os estudantes) tentam aprender ao mesmo tempo, a escola que nasceu com a modernidade.

$\mathrm{Na}^{21}$ Ratio Studiorum há um capítulo denominado "Dos exames escritos e orais”, em que definem-se as regras avaliativas que conduziriam os exames dos educandos. Tais regras revelam o quão conservadores ainda somos nos dias atuais. Nas disciplinas de Português e Matemática tais regras se revelam atuais, apesar de terem sido promulgadas há mais de

\footnotetext{
${ }^{21}$ A Ratio Studiorum fora pensada para ordenar as instituições de ensino de uma única maneira, com vistas a permitir uma formação uniforme a todos que freqüentassem os colégios da Ordem Jesuítica em qualquer lugar do mundo. Serviria de base comum que serviria de suporte do trabalho dos jesuítas. Em todos os lugares essas normas deveriam ser seguidas da maneira como estavam prescritas no documento, em coerência com os preceitos e os interesses da Igreja Católica. A elaboração de regras pelos colégios das diferentes localidades, que trabalhavam com realidades distintas, serviu para que os pontos positivos de cada uma delas fosse aproveitado para a elaboração final do documento. Até a redação definitiva, muitas correspondências foram trocadas e muitas críticas, experimentações e correções foram feitas. O documento final publicado em 1599, intitulado Ratio atque Institutio Studiorum Societatis Iesu, compõem-se de trinta conjuntos de regras que foram analisadas em nossa pesquisa. Trata-se de um detalhado manual com a indicação da responsabilidade, do desempenho, da subordinação e do relacionamento dos membros da hierarquia, dos professores e dos alunos. Além de ser também um manual de organização, avaliação e administração escolar. A metodologia é bastante pormenorizada, com a sugestão de processos didáticos para a aquisição de conhecimento e incentivo pedagógico para assegurar e consolidar a formação do aluno.
} 
quatrocentos anos.

As regras referem-se a rituais que deverão ocorrer nos dias de provas objetivando assim que o processo de avaliação ocorra sem nenhuma surpresa e seja padronizado para todos. Citemos um trecho do documento dos jesuítas: "no dia das provas é vedado a todo e qualquer estudante o empréstimo de material e a comunicação entre dois pares que participem do processo. Após o término da prova, o estudante deverá recolher seu material e entregar a prova concluída ao Prefeito de Estudos ${ }^{22}$ e sair sem se comunicar com outrem da sala de aula”; em outro trecho aparece:“o estudante que permanecer na sala de aula, após um colega ter saído, não poderá mudar-se de lugar de onde está sentado para o lugar daquele que já terminou sua prova e saiu. A prova só voltará a ser apreciada após correção pelo responsável”. Nada mais atual, não é mesmo?

Na Didática Magna, publicada em 1632 pela primeira vez, pelo bispo protestante John Amós Comênio, no capítulo intitulado "Leis para a Boa Ordenação da Escola” há semelhanças cruciais com as práticas examinativas atuais. Em uma das passagens da didática Magna, Comênio diz: “(...) que estudante não se preparará suficientemente bem para as provas, se ele souber que, de fato, as provas serão para valer?”23.

Nas "Leis da Boa Ordenação da Escola”, Comênio define que na escola, devem existir, exames de hora em hora, de dia em dia, de semana em semana, de mês em mês, de semestre em semestre, de ano a ano. E acrescenta ainda que o poder público deve nomear um personagem chamado "Scholarca" (aquele que tem o poder sobre a escola), que deve ter a responsabilidade de elaborar a aplicar, anualmente, por ocasião do fim do ano letivo, uma prova em todas as escolas, tendo em vista saber como estavam funcionando, independentemente do acompanhamento de cada estudante, por si. Interessa nesse encaminhamento, examinar a escola, não o estudante.

Para Romão (2011), ambas as pedagogias, a católica e a protestante, expressam o espírito da época e marcaram época, uma vez que seus pressupostos refletem até os dias atuais em nossas salas de aula. Propõem uma educação "disciplinada", centrada no professor como autoridade pedagógica, nos conteúdos humanísticos clássicos e na constituição de uma mente lógico discursiva, tendo como objetivo constituir, no aluno, um ser humano subserviente e conformado e ao mesmo tempo dotado de cultura geral e capacidade de argumentar logicamente ${ }^{24}$.

\footnotetext{
${ }^{22} \mathrm{O}$ Prefeito de Estudos era o Administrador Acadêmico de um Colégio Jesuítico; na data dos exames, era ele quem aplicava as provas e acompanhava os estudantes durante o período disponível para respondê-las.

${ }_{23}$ Importa observar que, na Didática Magna, são muitos os conselhos que Comênio dá ao educador para que ele possa manter a atenção e disciplina dos educandos. Como não trataremos aqui desses conselhos, indicamos o livro do próprio autor, que se encontra traduzido pela Fundação Calouste Gulbekian, Lisboa, Portugal.

24 A pedagogia que emerge da confluência das teorias pedagógicas jesuítica e comeniana constitui o que hoje denominamos de Pedagogia Tradicional que, posteriormente, no século XIX, incorporou também as contribuições ISSN 2526-2882
} 
Conforme nos salienta Luckesi (2009), a pedagogia que emerge da confluência das teorias pedagógicas jesuítica e comeniana constitui o que hoje denomina-se de Pedagogia Tradicional que, posteriormente, no século XIX, incorporou também as contribuições de Johann Friedrich Herbart (1716-1841) ${ }^{25}$. A segunda razão que nos prende à prática dos exames escolares tem a ver com os seus vínculos com a sociedade burguesa.

Demo (1996) reintera que a Pedagogia Tradicional, como expressão da sociedade burguesa, do ponto de vista psicológico, usou a díade culpa e castigo como recurso de controle social, impondo um modo supostamente correto de agir e a submissão. O castigo, nas suas múltiplas manifestações, que ia desde o castigo físico, o encarceramento (ficar sozinho sem merenda na sala de aula, por exemplo), até a submissão pelo silêncio, foi o recurso mais comum utilizado por tal pedagogia para submeter os educandos aos padrões de conduta considerados corretos.

Não é sem um comprometimento ideológico que, ainda hoje, praticamos em nossas escolas regras e prescrições estabelecidas nos séculos XVI e XVII. Nesse contexto fica evidente que vivemos sob a égide do modelo burguês de sociedade, na qual o poder é centralizado e hierarquizado, sendo que a prática pedagógica o reproduz como uma de suas mediações (LUCKESI, 2009). As taxas estatísticas do fracasso escolar, principalmente em Matemática onde acumulamos posições lamentáveis nos exames nacionais e internacionais, em nosso país, refletem sobejamente esse modelo de sociedade, onde a exclusão escolar reproduz o modelo de exclusão social.

A reprodução do modelo de autoridade e a prática de exclusão constituem-se como produtos da prática dos exames, através de provas e testes. Essa prática dos exames reproduz, assim, o modelo da administração do poder na sociedade, ignorando, ou no mínimo, subjuga despudoradamente a aliança primordial que deve estar presente na relação professor e aluno.

\section{Avaliar em Matemática para legitimizar práticas inclusivas}

Os professores, em geral, argumentam que avaliar é difícil, pois toda a carga fica sob a responsabilidade do corpo docente. Preparar provas, corrigí-las e ainda ter que dar o retorno ao aluno perfaz-se num processo desgastante e ingrato. Assim o que faz a grande maioria senão repetir o que foi feito na sua graduação, ou seja, não questiona sua prática e repete o que LUCKESI (2009) denomina de senso comum sedimentado ${ }^{26}$.

Muitos docentes na área de Matemática questionam, "Como avaliar uma ciência

de Johan Friedrich Herbert (1776 - 1841), educador alemão que desenvolveu os cinco passos formais do ensino, que, de certe forma, também utilizamos até hoje em nossas prática didática escolar

${ }_{25}$ Educador alemão que desenvolveu os cinco passos formais do ensino, que, de certa forma, também utilizamos até dos dias atuais em nossa prática didática escolar.

${ }^{26}$ Por "senso comum sedimentado", Luckesi entende o senso pelo qual praticamos nossos atos no cotidiano sem nos questionarmos criticamente o que eles significam. Seguimos o caminho mais comum, massificado. ISSN 2526-2882 
exata, senão através de provas, instrumentos que garantem a manutenção da natureza científica e racional da Matemática?”, "Que garantias de que houve ou não aprendizagem, senão através da aplicação de instrumentos padronizados (provas escritas e testes) e aplicados todos ao mesmo tempo para os alunos?”.

Pode até não perceber, mas o professor contradiz-se nesse momento. Reclama que toda a carga de notificar, avaliar, certificar e decidir a vida do aluno fica inserida no seu cotidiano, tornando-se insuportável muitas vezes, entretanto assume que é o único capaz de aquilatar a aprendizagem discente, utilizando para tal um legítimo instrumento da exclusão, a prova.

A prova, em si, não merece ser tomada como a causa do fracasso escolar do aluno. Entretanto, vem sendo utilizada pelo professor como instrumento propiciador de fracasso escolar, evasão e exclusão, pois perfaz-se como um instrumento que ignora a diversidade cultural do aluno, seus métodos extra-escolares e o mais grave, tenta padronizar a diversidade que cada um traz intrínseco às suas vivências.

Apesar das contradições, existem outras possibilidades reais de se avaliar em Matemática, sem que se conceba argumentos pró assepsia e mantenedor de crenças que ambicionam a manutenção da exatidão em fazer Matemática, abrindo mão de exames disfarçados de avaliação, optando assim por questionar o monopólio instituído pela pedagogia tradicional, espelho da sociedade burguesa e neoliberal.

Ao optar por avaliar de fato, o educador matemático colocar-se-á contra os ditames pré-estabelecidos, primeiramente. É imprescindível que toda a submissão seja revogada e o educador comece a refletir e caminhar por outros lugares na sua prática docente. A Matemática nesse caso não poderá ser concebida como uma disciplina para quem tem dom ou para poucos, isto é, não será externa e aversiva, mas sim interna e criativa (VASCONCELOS, 1998)

Nesse contexto, o ato pedagógico será subsidiário do desenvolvimento do aluno e esse também se constitui como objetivo geral das práticas avaliativas legítimas. Estão suspensas ações que reifiquem os exames para guiar, obrigar e submeter os alunos aos estudos forçados, com ameaças e temores. Ao optar-se pela Avaliação, o professor amplia seu campo de atuação, torna-se o agente que buscará a aliança do ensino-aprendizagem com o diagnóstico e regulação das aprendizagens efetuadas (PERRENOUD, 1999).

De acordo com Luckesi (2009), uma boa indicação para o trabalho educativo, e como não poderia de ser também avaliativo, é começar por onde há vida, opondo-se às condutas pedagógicas que visam o lado frágil dos educandos, expondo-os ao ridículo, como recurso pedagógico, produzindo, na maior parte das vezes humilhação, vergonha e retraumatização. $\mathrm{O}$ caminho a ser seguido não é o de desqualificar, mas sim acolher e qualificar.

$\mathrm{O}$ argumento utilizado por muitos professores de Matemática que é difícil julgar se ISSN 2526-2882 
houve ou não aprendizagem, a não ser através de instrumentos padronizados e arquitetados para funcionar em cinqüenta minutos, como se esse tempo pudesse representar uma homogeneidade que, sabemos é artificial e perigosa nas salas de aulas, se vê enfraquecido num contexto de avaliação legítima.

Os resultados das avaliações em Matemática, nos diversos níveis de ensino, de qualquer órgão nacional ou internacional, estão disponíveis nos variados meios de comunicação, retratam o quanto excluímos e rechaçamos aqueles que não se adequam ao formalismo das práticas avaliativas. Necessitamos sim mudar as ações docentes.

Ao invés de crer que estamos ensinando e os alunos estão aprendendo, necessitamos, num primeiro momento, diagnosticar o porquê de em Matemática a aprendizagem estar tão caótica e insípida. Muitos estudantes alegam que nada do que lhes é ensinado faz sentido ou está conectada a nada que o rodeie.

O diagnóstico e a regulação dos saberes são competências inerentes e indissociáveis da prática docente, seja ele de qual área for (PERRENOUD, 1999). A avaliação da aprendizagem no ensino, então não deve ser um fim, um ato isolado e pré-determinado, mas sim um ato integrado e contínuo com todas as outras atividades escolares. Para Japiassu (1976), enquanto se ensina, se avalia, ou enquanto se avalia, se ensina.

Neste contexto, a prática da avaliação da aprendizagem desperta no professor a importância do vínculo com seus quefazeres profissionais, a necessidade de formação contínua e continuada, atenção pela e cuidadosa em todas as intervenções junto aos alunos e a flexibilidade no relacionamento com os agentes escolares. Praticada de forma prudente e reflexiva, a avaliação em Matemática estará posta para subsidiar, não só o almejado desenvolvimento lógico-matemático do aluno, mas, sobretudo, o desenvolvimento cognitivo referente ao papel que esse aluno exerce na sociedade no caminho de sua trajetória existencial, estando a serviço da construção de sua experiência de vida.

\section{O Ato de Avaliar em Matemática - Momentos e Decisões Cruciais}

Embora muitos possam discordar, a Matemática perfaz-se na área do conhecimento onde todos os focos estão voltados quando se pratica a avaliação. Os resultados dos exames nacionais e internacionais estão aí para evidenciar tal fato. No entanto estão os professores de Matemática preparados para avaliar a aprendizagem dos alunos? Em que consistiria o ato de avaliar o rendimento da aprendizagem matemática do aluno?

Compartilhamos das idéias de Luckesi (2009) no que concerne ao ato de avaliar na sala de aula contemporânea e, cremos que suas idéias bem podem orientar as práticas avaliativas docentes, restaurando o caráter processual e contínuo do ato.

Nesse sentido, o ato de avaliar em Matemática implicaria dois processos articulados 
e indissociáveis: diagnosticar e decidir. De acordo com Luckesi (2009), não é possível uma decisão sem um diagnóstico, assim como não faz sentido um diagnóstico, sem uma consequente decisão.

Primeiramente, trataremos do ato avaliativo diagnosticar. Em Matemática é muito usual ignorar os conhecimentos discentes extra-escolares. Ao adentrar os portões da escola, procura-se limitar ao máximo as influências da matemática da rua que, segundo muitos embotaria e vulgarizaria a essência da matemática escolar. É importante citar também a cultura matemática dos pré-requisitos, ou seja, o aluno está mal ou será retido, pois não aprende, uma vez que não possui os pré-requisitos necessários para aprender os conteúdos seqüenciais oferecidos por seus professores.

A ato avaliativo de diagnosticar é composto de dois momentos indissociáveis: $a$ constatação e a qualificação do objeto da avaliação.

O termo diagnosticar tem origem etimológica no grego diagnostikós, que significa capacidade de discernir, de distinguir algo entre coisas dadas, que, em última instância, significa conhecer através de dados. Assim tomamos como primeiro ato do professor de matemática que quer avaliar seus alunos, diagnosticar o que cada aluno sabe, suas experiências, escutá-los, afim de poder conhecer cada aluno em virtude dos dados que estes apresentarão ao professor.

Um diagnóstico é um conhecimento que o professor adquire através dos dados que qualifica, permitindo ao regente de sala de aula decidir e intervir. Ação, sem conhecimento, é puro ativismo. A compreensão oferece base para uma ação eficiente e eficaz (LUCKESI, 2009).

O primeiro elemento a que se deve atentar o professor disposto a ensinar Matemática é o da constatação. A constatação produz uma descrição do objeto do ato de conhecimento, expressando a configuração desse objeto, tendo por base suas propriedades presentes, como estão no momento. Cabe ao professor de Matemática ter em mente que o ato de avaliar, como todo e qualquer ato de conhecer, inicia-se pela constatação.

Por exemplo, ao tomar contato com o aluno, cabe ao professor a ação de constatar o estado em que este se encontra em termos de conhecimentos matemáticos, que experiências já vivenciou e onde, que crenças possui sobre determinados saberes, isto é, cabe ao professor investigar a fundo o que sabe e o que não sabe o aluno, buscando criar uma imagem que revelará, aproximadamente, o que de verdade sabe o aluno dos conteúdos matemáticos.

A constatação oferece a base sólida para a segunda parte do ato avaliativo de diagnosticar que é o ato avaliativo de qualificar, ou seja, atribuir uma qualidade, positiva ou negativa, ao ente que está sendo avaliado. Para Luckesi (2009), somente a partir da constatação é que qualificamos o objeto da avaliação, isto é, assentados nos dados constatados, o professor poderá atribuir uma qualidade. Porém é importante que fique claro que essa 
qualificação não é arbitrária, mas se dá a partir de um determinado padrão, de um determinado critério de qualidade utilizado pelos professores e colocado em prática em seus atos avaliativos.

Nesse contexto, o ente a ser avaliado está envolvido em um contexto de significados que o envolve. Ao professor envolvido no processo de avaliar, não basta somente considerar os dados em foco, qual seja constatar, mas, sobretudo, considerar o quadro de referência de significados que estão sendo utilizados nos critérios de qualificação (RABELO, 1998).

O ato avaliativo de qualificar o objeto da avaliação exige um padrão (ou um critério) de qualificação, pois que esta se dá pela comparação das características descritivas do objeto da avaliação com o critério de qualificação deferido pelo professor. Se a descritiva for compatível com o critério, a qualidade será positiva; caso contrário, será negativa. Em uma redação, caso o critério seja ausência absoluta de "erros ortográficos", a mesma será considerada qualitativamente adequada, caso esses erros não apareçam no seu desenrolar.

Ao diagnosticar um objeto matemático de avaliação (por exemplo, o aluno saber calcular o mmc de números), há ainda uma etapa da qual não pode prescindir o professor de Matemática: decidir ou proceder à tomada de decisão. Segundo Luckesi (2009, p. 72),

o ato de qualificar, por isso, implica, obrigatoriamente, uma tomada de decisão, positiva ou negativa, a respeito do objeto, pessoa ou ação, que está sendo avaliado, o que, por sua vez, conduz a uma tomada de decisão. Tomada de decisão, aqui, significa decisão de intervir na realidade avaliada.

É mister enfatizar que o ato de avaliar não é um ato neutro, corriqueiro, que se encerra na sua constatação e consequente qualificação. Avaliar é um ato dinâmico que implica, mais cedo ou mais tarde em "decisão do que se fazer". Abstendo-se o professor desse ato de decidir, o ato de avaliar de verdade não se efetua, devido nessa situação não dar sustento às melhorias dos resultados almejados. Inumeráveis são os casos onde o professor relata que ensinou, mas o aluno é que não aprendeu. Os resultados aparecem somente no momento das provas, quando muitos professores apenas constatam que houve deficiente aprendizagem e qualificam o aluno como inapto.

Em suma dentro da perspectiva pedagógica escolhida e vivenciada pelo professor, é possível utilizar a avaliação da aprendizagem matemática, tomando o verdadeiro significado da avaliação. Para tal, faz-se necessário que o professor qualifique-se, de forma a saber organizar suas ações de ensino e avaliativas. É imprescindível que o professor saiba, a partir dos dados colhidos nas avaliações, possa trabalhar esses dados, isto é, diagnostique as situações que estão ocorrendo, para uma tomada de decisão visando proceder a uma intervenção e melhorar os resultados advindos do processo avaliativo.

Contrapondo-se meramente a praticar exames de Matemática que apenas, como já citamos, julgam e classificam os alunos, primando por práticas privilegiadoras do pré-requisito ISSN 2526-2882 
e da memorização, para proceder à avaliação, o professor de Matemática deve (KISTEMANN JR, 2004):

- definir com clareza aquilo que deseja (objetivos);

- coletar os dados relevantes da realidade (no decorrer da ação ou em momentos sucessivos da ação);

- buscar conhecer, antes de qualquer ação avaliativa, o que sabe o seu aluno, suas experiências e crenças;

- qualificar os alunos diante do que espera como sendo o necessário;

- reavaliar-se sempre e de forma consciente e contínua, ou seja, estar atento caso a qualidade esperada não tenha sido atingida, buscando realizar novos momentos de avaliação aliados a momentos de regulação da aprendizagem;

- ser ou tornar-se um agente investigativo de novas formas de avaliar, diagnosticar, constatar e qualificar seus alunos, buscando criar ou usufruir de instrumentos de avaliação que promovam a aprendizagem matemática reflexiva.

Muitos podem argumentar ser de difícil execução as tarefas anteriores buscando assim a gênese de um professor que além de bem ensinar deve saber aquilatar a aprendizagem de seus alunos e avaliá-los de forma contínua e inclusiva, principalmente em Matemática, ciência ainda tida como fria e racional.

Porém, se o professor de Matemática estiver ciente de que a avaliação é um ato diagnóstico que serve de subsídio para uma tomada de decisão na perspectiva da construção da trajetória do desenvolvimento de seu aluno, poderá utilizardos mais variados instrumentos disponíveis, para observar as condutas aprendidas e desenvolvidas dentro e fora da sala de aula (PERRENOUD, 1999).

Diante disso, deve ficar claro para o professor que o que importa, em primeiro plano, não é o instrumento de coleta de dados para a avaliação, mas sim a avaliação propriamente dita, em função da qual estão configurados os instrumentos. Em seguida importa não os instrumentos, em si, mas, sim, a compreensão do ato de avaliar.

\section{Palavras Finais - Reflexões para sempre}

De acordo com as reflexões que fizemos até então, o leitor ou a leitora poderia , de forma perfeitamente pertinente colocar a seguinte questão: “Os exames são inúteis?” ou "Diante do enorme contingente de pessoas para um determinado cargo (seja estudante ou profissional) e o reduzido número de vagas, como proceder à escolha dos que ocuparão as vagas?”.

De fato, tais questões mais do que pertinentes são atuais e merecem ser feitas. ISSN 2526-2882 
Entretanto, é preciso demarcar bem o território em que se deve avaliar e o território em que se deve examinar. Para Luckesi (2009), no geral, os exames são úteis e necessários nas situações que exigem classificação, como em concursos, aos quais, cada um de nós, aqui e acolá se submete, tendo em vista concorrer a um emprego ou tendo em vista o acesso a algum programa de estudo, pesquisa, ou coisas semelhantes.

Os exames também são úteis em situações que exigem uma certificação de conhecimentos, como, por exemplo, para acesso à Ordem dos Advogados, ou a uma Sociedade Médica. Nestas situações, não estão em questão o ensino e a aprendizagem. Importa que o candidato a uma vaga ou certificação pública manifeste aquilo que efetivamente já aprendeu e sabe, isto é, importa a aprendizagem concluída (LUCKESI, 2009).

Na disciplina de Matemática, evidencia-se uma quase unanimidade que afirma ser impossível não avaliar através de provas escritas e individuais. Tal crença decorre da necessidade em se garantir a legitimidade do processo avaliativo, que deve sempre embasarse na objetividade das ações avaliativas, tornando o processo lícito e inquestionável.

Em contraposição, na sala de aula de Matemática, os exames não fazem nenhum sentido, tampouco a classificação ou a certificação se ensejam necessárias, uma vez que a sala de aula é um espaço de aprendizagem, da construção do conhecimento matemático, do acerto, do erro e não de demonstração do que já se sabe. De acordo com Hoffman (2011), a sala de aula é o lugar em que se aprende e não o lugar onde se concorre a alguma coisa.

Desse modo, em termos de acompanhamento da aprendizagem do educando, nas salas de aulas, em geral, deve predominar o diagnóstico, pois que ele subsidia a regulação das aprendizagens, garantindo um processo construtivo e contínuo, propício à mediação docente, ao invés de predominar o exame como recurso classificatório, próprio de situações de concorrência ou de demonstração de saber (PERRENOUD, 2004).

Por fim, um trabalho pedagógico que se sustenta numa pedagogia inclusiva, da avaliação diagnóstica e aprendizagem regulada na interação professor-aluno, investe no processo, em detrimento do produto. Nesse ponto entendemos que não são as opções avaliativas (ou examinativas) que determinarão os procedimentos pedagógicos, mas sim tais procedimentos pedagógicos que determinarão as práticas avaliativas (ou examinativas).

De todo o modo nunca devemos perder o foco que o mais importante é a aprendizagem discente e seu desenvolvimento cognitivo gradativo, respeitando-se seu ritmo e tempo escolar e extra-escolar.

\section{Referências}

DEMO, Pedro. Avaliação sob olhar propedêutico. $6^{\circ}$ ed. Campinas: Papirus, 1996. 
HOFFMANN, Jussara. Avaliação mediadora: uma prática em construção da préescola à universidade. 31. ed. Porto Alegre: Mediação, 2011.

JAPIASSU, H. Interdisciplinaridade e patologia do saber. Rio de Janeiro: Imago, 1976.

KISTEMANN JR., Marco A. O erro e a tarefa avaliativa em Matemática: uma abordagem qualitativa. Dissertação (Mestrado em Educação) - Faculdade de Educação, Universidade Federal do Rio de Janeiro. Rio de Janeiro, 2004.

KISTEMANN JR., Marco A.; PENNA-FIRME, André B. O erro e a tarefa avaliativa em matemática: uma abordagem qualitativa. Revista Ensino de Ciências e Engenharia, v. 1, n. 1, p. 38-53, jan./jun. 2010.

LUCKESI, Cipriano C. Avaliação da aprendizagem escolar: sendas percorridas. Tese (Doutorado em Filosofia da Educação) - Pontifícia Universidade Católica de São Paulo. São Paulo, 1992.

LUCKESI, Cipriano Carlos. Avaliação da aprendizagem escolar: estudos e preposições. 20. ed. São Paulo: Cortez, 2009.

LUCKESI, Cipriano Carlos. Avaliação da aprendizagem como componente do ato pedagógico. São Paulo: Cortez, 2011.

PERRENOUD, Philippe. Avaliação: da excelência à regulação das aprendizagens entre duas lógicas. Tradução de Patrícia C. Ramos. Artmed: Porto Alegre, 1999.

PERRENOUD, Philippe. Três condições para aprender. In. Os ciclos de aprendizagem: um caminho para combater o fracasso escolar. Porto Alegre: Artmed, 2004. p. 55-66.

RABELO, E. H. Avaliação: novos tempos e novas práticas. Petrópolis, RJ: Vozes, 1998.

ROMÃO, José Eustáquio. Avaliação dialógica: desafios e perspectivas. São Paulo: Cortez, 2011.

VASCONCELOS, Celso dos Santos. Avaliação: concepção dialética libertadora do processo de avaliação escolar. São Paulo, Libertad, 1998.

\section{Biografia Resumida}

Marco Aurélio Kistemann Jr. é Doutor em Educação Matemática (UNESP) e líder do Grupo Pesquisa de Ponta (UFJF) com pesquisas nacionais e internacionais em Avaliação, Aprendizagem Matemática, Educação Financeira e Modelagem 
Matemática.

Link do Lattes: http://lattes.cnpq.br/o321706175094911

e-mail: kistemann1972@gmail.com

Ruth Brugger Glanzman é Licencianda em Matemática (UFJF), foi bolsista PIBID e realiza pesquisas no grupo Pesquisa de Ponta (UFJF) na área de Avaliação da Aprendizagem Escolar.

Link do Lattes: http://lattes.cnpq.br/0407005846131535

e-mail: pesquisadepontaufjf@gmail.com 